\title{
Relationship between Generic Skills and Employability Skills: An Exploratory Study in the Context of New Zealand Postgraduate Education
}

\author{
ZHENFENG ZHAO \\ Otago Polytechnic Auckland International Campus, New Zealand \\ francis.zz@yahoo.com \\ INDRAPRIYA KULARATNE \\ Otago Polytechnic Auckland International Campus, New Zealand \\ indrapriya@op.ac.nz
}

\begin{abstract}
The lack of employable-ready graduates has been an issue for New Zealand Tertiary education providers. Besides universities, Institutes of Technology and Polytechnics (IтPs) in New Zealand contribute a larger proportion of training employees to the job market. The objective of this study is to evaluate how the generic skills delivered by IтPs contribute to graduates employability skills. A literature review was carried out to investigate the most important generic skills for the present New Zealand job market. Data collected and analysed from three groups of participants. The results of this research provide an understanding of how graduates successfully acquire their generic skills during their studies in ITPS and the findings explain how graduates acquire and improve these generic skills. The results indicate that most graduates start their studies at ITPS with some generic skills, however, all of them agree that study at IтPS enhances these skills.
\end{abstract}

Key words: generic skills, hard skills, soft skills, employability skills, thematic analysis

\section{Introduction}

The value of a degree to offer employability is diminishing in tertiary education (Jassal and Clark 2016). In 2016, PricewaterhouseCoopers indicated that both graduates and employers had concerns about whether the investment in a university qualification is able to improve graduates' employability level. Ideally, students are supposed to graduate from their Tertiary Education Institutions (TEI) 
with their expected skills, to meet the requirements of relevant industries in their careers. Whereas, Ferguson (2010) conducted research which showed that neither employers nor students understood what were the exact skills and capabilities received from their qualifications. Sometimes the qualification did not even match the industries' needs. Without a clear understanding of required skills from both perspectives, the value of tertiary education qualification would be reduced. As a result, the gap between graduates and workready graduates has been an issue for tertiary education providers which needs to be discussed and improved (Ferns, Dawson, and Howitt 2019).

Ako Aotearoa National Centre for Tertiary Teaching Excellence (Duignan et al. 2018) reported that employability skills are vital for finding and retaining a job. Employees are essential as part of the functional chain and are required to have particular employability skills to perform well in their daily jobs, and therefore students (future employees) need to be prepared with employability skills prior to graduation (Cabellero and Walker 2010). Compared to some targeted skills in certain industries, generic skills could be gained by students during studies in tertiary institutions. Mayer (1992) defined generic skills as these which are able to be applied to any workplace, instead of skills specific to a certain occupation or industry. Kearns (2001) showed that generic skills are basic skills necessary to obtain and retain employment. Moreover, Bridgstock (2001) emphasised the importance of generic skills as transferable within diverse occupations and positions, contributing to sustainable and immediate employability. As a result, generic skills are essential elements which could determine employability skills. In order to gain employability skills, Cassidy (2006) demonstrated that such could be directly delivered through the teaching process, in terms of specific educational practices, such as teacher attribute and skill acquisition.

New Zealand is well known for its tertiary education. The study of Fraser et al. (2019) pointed out that Institutes of Technology and Polytechnics (IтP) in New Zealand, as compared to Universities and Private Training Establishments (PTE), tend to enrich their students with multiple employability skills. To achieve this target, ITPS normally provide a set of class activities, workshops, projects and internships offering opportunities for students to practice their skills.

A significant amount of literature was published on generic and employability skills, but most of them contained theoretical information, and offered policy recommendations and perspective advice (Wickramasinghe and Perera 2010). The majority of these studies

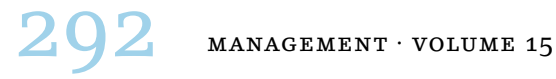


focused on examining the experiences of difference TEIs and the remedial actions taken to satisfy employers by improving skills of graduates. Several issues were identified in this research and they are: meeting the skill expectations of graduates after completing their studies, skills mismatch between graduates gained during their studies and what industry needs and gap between graduate and work-ready graduate in terms of skills. This research aims to explore how generic skills gained by graduates from management qualifications in New Zealand ITPS, contribute to their employability skills.

\section{Literature Review}

Every TEI, is facing crucial changes in teaching students in this rapidly changing business world (Bedwell, Fiore, and Salas 2014). The conventional approach in the teaching and learning process is mainly based on knowledge delivery. This is questionable at present, as a result of the new knowledge required in emerging jobs (Singh and Gera 2015). Problem solving and critical thinking should embrace dynamic trends of experiential learning within the entire spectrum of expertise. This includes emotional, rational and spiritual knowledge (Bolisani and Oltramari 2012). A study by Massaro, Bardly, and Garlatti (2016) showed that business schools are very slow in adopting ethical principles and soft skills. Only a fraction of generic skills is practiced within the business school curricula (Bratianu and Vatamanescu 2017). The gap between expected outcomes of study and actual performance, might lead to difficult challenges for graduates, and negative feedback on the education providers. Hence, it is crucial to address, or at least discuss this issue, in order to offer quality education to students. As a result, this research proposes to evaluate how skills gained before the students graduate contribute to their employability skills.

\section{Generic Skills}

According to the study of Mayer (1992), generic skills, compared with other specific skills, could be applied to general industries instead of to a specific occupation. Curtis (2004) indicated that a skill is generic if it could be manifested by different observers in many different contexts. Besides as some hard skills generally required in various occupations, soft skills are also significant in the modern world with its nature of rapid changing. For instance, Chan and Fong (2018) identified communication, problem-solving and critical thinking as generic skills. These skills are critically based on industrial experience since they are beneficial for the efficiency and pro- 
ductivity of work. These give a competitive advantage as they are intangible resources (Bratianu and Vatamanescu 2017). As a result, generic skills are valuable for graduates and students by increasing their opportunities for employability (Wickramasinghe and Perera 2010). Additionally, generic skills as the key set of skills for students who are looking to commence their career. Furthermore, Bratianu (2015) demonstrated that generic skills could directly contribute to dynamic knowledge in management as employability skills. The following section explains several generic skills which are directly connected to employability skills. In order to easily identify the generic skills, this research categorised them into soft skills and hard skills based on whether the skill was technology related.

Soft Skills. Generally, soft skills refer to human capabilities where behavioral and interpersonal skills are required to apply technical knowledge and skills while working (Weber et al. 2011). Moss and Tilly (1996) defined soft skills as technical or formal knowledge, in which traits and abilities are associated with attitude, personality and behavior. Kechagias (2011) defined soft skills as socio-emotional skills essential for career development, social interaction and employment success. Regarding soft skills in the management context, Marando (2012) suggested communication, leadership, influencing, decision-making, expectations management and problemsolving as examples. Innovation, not only technological but also nontechnological, is one of the core competency skills for leaders to improve the productivity of their teams (Mohnen and Hall 2013). Based on the study of Martino and Bartolone (2011), the essential soft skills associated with innovation, comprised strategic influencing, quick study, passion and optimism, entrepreneurial orientation, communication skills, tolerance for uncertainty and the talent for relationship building and maintenance. Additionally, there is a skill, innovation leadership which is also related to innovation. Carmeli, Gelbard and Gefen (2010) described innovation as a leadership characteristic allowing leaders to encourage, orient, and improve relationships and to develop trust among teammates in the workplace.

As previously mentioned, contemporary research has investigated on many soft skills. Of all soft skills discussed and investigated in the literature reviewed for this study, only three soft skills were selected. The criteria for selecting these skills are widely discussed in the literature, and also how these skills are important in terms of employability in the New Zealand context. The selected soft skills for this study are; relationship building, innovation leadership and the tolerance for uncertainty. Additionally, these skills were exten-

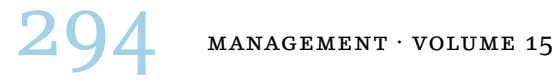


sively discussed in the literature resources used for this study (e.g. Carmeli, Gelbard, and Gefen 2010; Kechagias 2011; Marando 2012; Martino and Bartolone 2011; Mohnen and Hall 2013; Weber et al. 2011).

Hard Skills. Rainsbury et al. (2002) stated that hard skills are a set of skills related to human technical knowledge. The concepts of hard skills in the management context has been listed as procedures, processes, techniques and tools (Azim et al. 2010). Furthermore, Marando (2012) described hard skills in project management, as the creation of the tangible delivery of a project in terms of schedules, diagrams, reports and budgets. Poisson-de Haro and Turgut (2012) described conceptual skills and technical skills, as hard skills, and they are core skills for managers. In addition, conceptual skills can represent cognitive practices such as curiosity, imagination and critical thinking (Scott and Vincent-Lancrin 2014). Of the hard skills mentioned above, three hard skills were selected for this research. They are the use of software, quick study, and conceptual thinking (Martino and Bartolone 2011; Rainsbury et al. 2002; Spencer and Spencer 1993). These hard skills have been investigated and discussed in detail in contemporary research. That was the main reason for selecting these three hard skills in this study.

\section{Employability Skills}

A common definition of employability skills is the capability to gain a job offer after graduation and then to maintain employment. For example, Hillage and Pollard (1998) defined employability skills as the ability to be employed, retain the job and to change to other more preferable employment with satisfaction. Yorke (2010) redefined employability skills similarly, as the capacity to receive an offer at graduate level, to retain that job or even to develop in a further career. Besides, some literature explains employability skills as essential skills, attributes, knowledge and understanding. Moreland (2006) indicated that employability skills consisted of a set of personal attributes, knowledge and skills which contributed to individual success, and to security in a career. Regarding detailed employability skills, Singh and Singh (2019) described these as communication, problem-solving and analytical skills. Ademiluyi (2019) also presented the diverse employability skills needed by business graduates as reliability, integrity, decision making and willingness to learn. Similarly, Nalawade, More, and Bhola (2019) analysed and found that thinking skills, business communication, conceptual skills and priority setting skills were functional employability skills in manage- 
ment. The above-mentioned employability skills used by Fraser et al. in their research in 2019. The same set of employability skills was used in this project and the reason was that they were associated with the generic skills related research discussed above. The employability skills selected for this research are communication, positive attitude, resilience, innovation, thinking skills, willingness to learn, teamwork, entrepreneurship, cultural competence and selfmanagement.

The plethora of literature focused on employability skills and they agreed on a skill gap between what graduates have and what employers expected, but they are still debating how big it is (Dearing 1997). There is an increasing need for further research on graduates' transition to work and their early careers and therefore, TEIS need to focus on skills that graduates might need in future during their employability and employers expect them to have (Connor and Shaw 2008). There are limited studies investigated on hard and employability skills specifically focused on postgraduate students from management study area. It is important to supply skilled employees to workforce and it can be considered a as a priority area that requires immediate attention due to the nature of competitiveness and growth of business sector in New Zealand (Fraser et al. 2019). This research was designed to explore the relationship between generic skills and employability skills of management postgraduates in New Zealand from the viewpoints of graduates, lecturers and employers.

\section{Methodology}

Qualitative data was collected using semi-structured interviews because it is a flexible method to achieve depth to this topic by probing and expanding the interaction between the interviewees and researchers. This project has two parts to achieve the research aim. First, the relevant literature was reviewed to identify generic and employability skills. Generic skills and employability skills have been predetermined through literature review and their importance in terms for finding employment in New Zealand as explained in the literature review section above. Second, semi-structured interviews were used to identify the relationship between generic skills and employability skills of graduates. The semi-structured interview questions were prepared based on the published literature (e.g. Bedwell, Fiore, and Salas 2014; Bratianu and Vatamanescu 2017; Carmeli, Gelbard, and Gefen 2010; Martino and Bartolone 2011; Wickramasinghe and Perera 2010).

Three participant groups interviewed during the data collection

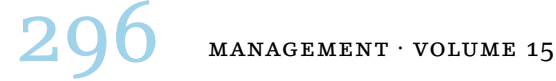


process. As the first group, five lecturers teaching postgraduate management qualifications from different ITPS, were interviewed. The second group included five graduates who had successfully graduated with a postgraduate qualification from above mentioned ITPS studied management. The third group consisted of five employers, managers of the previously mentioned group of graduates.

Thematic analysis suggested by Braun and Clarke (2006) and systemised by Maguire and Delahunt (2017) was used to analyse the data. An additional step was added to compare the interview answers from graduates (employees), and employers (managers), to identify how graduates acquired their employability skills. As the first step, initial codes were generated, the main objective being to organise data in a systematic and meaningful way. The coding method was based on research questions. Every segment of text which seemed relevant to the research questions was picked out. At the end of this phase, codes from graduates and lecturers were extracted as preliminary ideas. In the second step, the employability skills revealed by the graduates were compared with the information provided by the employers. To capture everything significant or relevant to the research questions, themes were defined as patterns to connect the codes. Javadi and Zarea (2016) suggested that the codes might overlap among small data sets, which led to the next stage of preliminary themes. During the last stage, all the codes of graduates and lecturers extracted previously were fitted into broader themes. These themes were organised specifically in relation to the research questions.

\section{Findings and Discussion}

The collected data were used to identify themes (and sub-themes) and 11 themes were identified. The themes were the degree of proficiency in skills, skills acquired or improved, skill contributor and skill outcome, feedback on course setting, relationship between employability skills, course expectation and setting, academic expectations, approaches and expectations (with sub-theme, essential activities and skills provider), how the generic skills were practiced (with sub-themes, generic skill practices and direct employability skill training), how the generic skills were mastered (with sub-theme, negation), and feedback on course setting.

The themes were built based on the objective narration of experiences and subjective description by each participant. For example, the themes degree of proficiency in skills and skills acquired or improved, described if the interviewees agreed with the interview questions that they gained the skills and how they evaluated their 
present skills and the feelings. One graduate stated that 'can bring more structured and detailed procedures into daily work' (Graduate 3), which explained that she was able to implement the skill into her daily job. Whereas, another participant stated that 'I didn't learn new things, but my skill was improved' (Graduate 4). Additionally, graduates' above-mentioned skills were highlighted by employers e.g. 'quite critical thinking and analysing' (Employer 4) and 'I have seen continuous instances of reviewing and reflecting on processes' (Employer 5). It could be seen that even though graduates had relevant experiences while studying, outcome might be different in how they mastered the skills eventually.

Some themes were extracted based on the participants' real experiences while studying. For instance, theme skill contributor and skill outcome based on the explanations and reasons given by the graduates during the interviews. One interviewee indicated that 'The group assignment and being leader in my team contributed to the innovation and leadership skills' (Graduate 1). It was categorised under skill contributor. Similarly, when a graduate said that 'Studying here give me more skills of thinking like planning and time management' (Graduate 5), this showed the skill outcome. Furthermore, skill contributor and skill outcome showed how they measured and reached the training target. The majority of answers directly explained how graduates enriched themselves with targeted skills. For example, in order to train the students' use of software skill, a lecturer said that 'I have introduced new software in my class to develop their thinking while preparing their assignment' (Lecturer 4). This was strengthened by the statement made by an employer 'She was able to help us use more online tools, because she had really learned it herself and she taught it to us as well' (Employer 2).

When the graduate provided any feedback, which seemed directly to answer the research questions this was included into the feedback on course setting theme. In situations where extra information was provided, then this was considered as relationship between employability skills.

The themes, course expectation and setting, academic expectations, and approaches and expectations were developed and supported in accordance with the lecturers' following statements 'What is the original expectation of the course?' (Lecturer 1), 'How the course setting achieves the target?' (Lecturer 2) and 'What is the performance?' (Lecturer 5). For instance, course expectation and setting described the initial target of current course setting as 'expecting high level of conceptual thinking from all postgraduate stu-

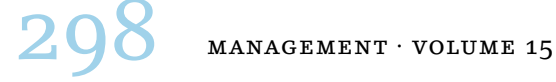


dents especially for level 9 courses' (Lecturer 2). The lecturer indicated that the objectives of course settings were to give the postgraduate students practice in thinking conceptually, especially the master's students. Thus, this theme indicated that the course setting had been intentionally framed with conceptual thinking skills practice in mind. Also, the lecturers gave some clear directions to the students to ensure they understood what they were required to do such as 'need to spend hours in reading and mastering the topic' (Lecturer 1). Moreover, some participants offered extra information which provided valuable messages. For example, a lecturer said that 'What they lack for me is critical thinking or mind mapping about putting things and all factors together' (Lecturer 4), which implied that the students might need to fill the gap of critical thinking, and how they could achieve that. On the other hand, an employer (Employer 2) mentioned that his graduate (employee) had good critical thinking and analysing abilities when involved in processes.

The analysis based on data collected from the lecturers', academic expectations theme indicated what the academic team's primary explanations were regarding the teaching outcome. While they were designing the course frame, a variety of elements were considered, and included in the programme, such as class activities and assessments. Core knowledge delivery and generic skills practices were integrated into the course preparations. This was supported by the following statements provided by two different lecturers: 'The use of software is one of the cores of this course' (Lecturer 2) and 'Leadership skills plus innovation comes together hand in hand through my courses' (Lecturer 3). The lecturers have skills in course delivery, unique teaching methods and clear teaching targets, for example 'Short-term practice plus experiential way of teaching can train students with generic skills' (Lecturer 3). To practice the employability skills, the courses were planned to expose the students to an external environment which would enrich them with more practical experiences. This was highlighted in these two statements: 'The assessments focus on ongoing New Zealand organisations which needs students to talk to people from those organisations' (Lecturer 2) and 'They will expand their networks which contributes to the employability skills' (Lecturer 5).

The next theme is approaches and expectations, with two subthemes, essential activities and skills provider. The sub-theme, essential activities refers to all the requirements in the study and learning process. To acquire the target skills, the students had to follow the guidance accordingly. This is different from the next sub- 
theme, as it might not be guided by the lecturers and explained as 'They have to do research online, so they are using internet extensively' (Lecturer 3) and 'It is a part of the assignment requirement for the students to conceptually think to certain level' (Lecturer 4). The sub-theme skills provider refers to all the factors which contribute to the students' generic skills while they were studying in ITPS. Those contributors comprise of assignments, class activities, available resources, and support from lecturers and relevant departments. These were covered in the following statements provided by the lecturers 'Both courses improve conceptual thinking and practice them in terms of assessment and group work' (Lecturer 1), 'They use on-line library for searching' (Lecturer 2) and 'I have introduced new software in my class to develop their thinking while preparing their assignments' (Lecturer 4). Some of the courses and on-campus activities directly enhanced the generic skills and employability skills of students. This fact was supported by 'We teach leadership skills in the paper Capabilities for Managers' (Lecturer 2) and 'There are a lot of activities going on campus in terms of relationship building like Diwali or Chinese mooncake festivals' (Lecturer 2). The sub-theme skills provider, described what the lecturers provided in order to develop students' generic skills. An employer stated about his graduate employee 'has a passion for developing her skills, very passionate about supporting the goals of the company and likes to research how to do things better' (Employer 3). The above employer's statement supported the theme of approaches and expectations highlighted by the lecturers.

To understand the relationships between the lecturers' expectations, and what graduates perceived, the theme of how generic skills were practiced was introduced with two sub-themes, namely generic skill practices and direct employability skill training. The first subtheme generic skill practices described what experience the graduates had in IтPS which contributed to these generic skills. The main contributors were group assignments, presentations and projects. They also had voluntary choices in terms of volunteer work, networking events, and participating as student service ambassadors. This fact was strengthened by employees' statements such as: 'I started as student ambassador', 'We have a lot of volunteer work and networking events which connect to recruitment people' and 'We practiced conceptual skill through a simulation game in Financial Decision Making' (Graduate 1).

The second sub-theme, how the generic skills were practiced, is direct employability skill training. This was the training that directly 
connected to employability skills improvement, and was mentioned by participants as valuable study experience. They were exposed to this in their courses at ITPs such as cross-cultural management, entrepreneurship and innovation, capabilities for managers and professional project. The Project Management course was mentioned by more than one graduate who agreed that this paper was useful in their current employment. In order to support the above argument Graduate 2 stated that 'Project Management is a very useful paper as I learned not only follow the deadlines for the budget but also try to predict some uncertainties. I have practiced Enterprise Resource Planning in Microsoft Project Management which helped my hard skills'. Some of the above generic skills were confirmed by employers. Examples are 'works well in a team' (Employer 1), 'It is interesting being able to pick somebody and then having somebody that actually fits the criteria' (Employer 2), 'She is able to embrace all other cultures in the office' (Employer 3), 'is highly culturally competent' and 'is much loved and highly valued member of the organisational community' (Employer 4).

The concept of skills acquisition in tertiary education was summarised as the theme of how generic skills were mastered with one sub-theme, negation. This was evaluated by the graduates themselves regarding the extent to which they mastered the generic skills, and how they were able to reflect those generic skills in their job, as employability skills. The analysis showed that generic skills improved. Even though the participants might already have had the skills before, the study experience still improved their existing skills and supported them with 'I improved all of them except the Cultural Competence and Teamwork which were totally new to me' (Graduate 2), 'The current course setting has strengthened the abilities to be more creative' (Graduate 3) and 'Studying here give me more skills of thinking like planning and time management' (Graduate 5). Some participants said they were able to bring generic skills to their current workplaces. They also believed that they had the capacity and capability to cope with general problems and to develop themselves using the lessons learned. This fact was embedded in the following statements 'Tolerance of uncertainty, it depends on situation and what resources I have on my hand' (Graduate 2), 'I can apply my leadership skills on my present workplace' (Graduate 3 ) and 'I can find another point of view for problem with innovation skills' (Graduate 5). The sub-theme of how the generic skills were mastered is negation. This presented all the unsure and negative feedback regarding the study outcomes. The participants offered diverse 
answers which lead to the sub-theme negation such as 'I didn't learn new things but only improved some of them' (Graduate 2), 'Conceptual thinking is a personal skill' (Graduate 3) and 'I am creative which is my nature. I don't feel studying at this polytechnic somehow affected us' (Graduate 4).

This analysis also considered lecturers' comments on current course content for the theme feedback on course setting. The lecturers provided their own opinions regarding course setting and skills training. It is surprising that the lecturers indicated more gaps than the graduates. This should be discussed and improved further. The main gap mentioned was the deficiency in course setting and students' initiatives. For example, by 'There is a need to focus more on conceptual thinking in the first few papers' (Lecturer 5).

This research was focused on graduates from New Zealand IтP sector and findings were important to future employers in terms of various generic and employability skills. The results showed the relationship between soft, hard and employability skills that current employers expect from graduates (figure 1). This study also reveals that how and what skills that employers and lecturers are looking from graduates and in what context. Additionally, it showed that how graduates acquired various skills during their academic journey in ITPS. The findings of the study will be helpful for future management students in terms of gaining their new skills.

\section{Conclusion}

This project explored how the graduates acquired their generic skills (which are eventually developed as employability skills) during their studies in IтPS. There were different definitions available for generic and employability skills in the literature. These skills are essential to secure a job in New Zealand job market and they are very important in most management occupations. The soft and hard skills are the two categories of generic skills. The soft skills mainly are interpersonal and cognitive. These intangible skills are coherent with social participation and success in the workplace. On the contrary, hard skills are mostly associated with technical elements, cognitive in nature, and are affected by IQ when involved in procedures, processes and tools.

Contextually, employability skills could be considered as the evolution of generic skills enabling graduates to be ready in the employment market. During the literature review stage, three soft skills (relationship building, innovation leadership and tolerance for uncertainty) and three hard skills (use of software, quick study and 


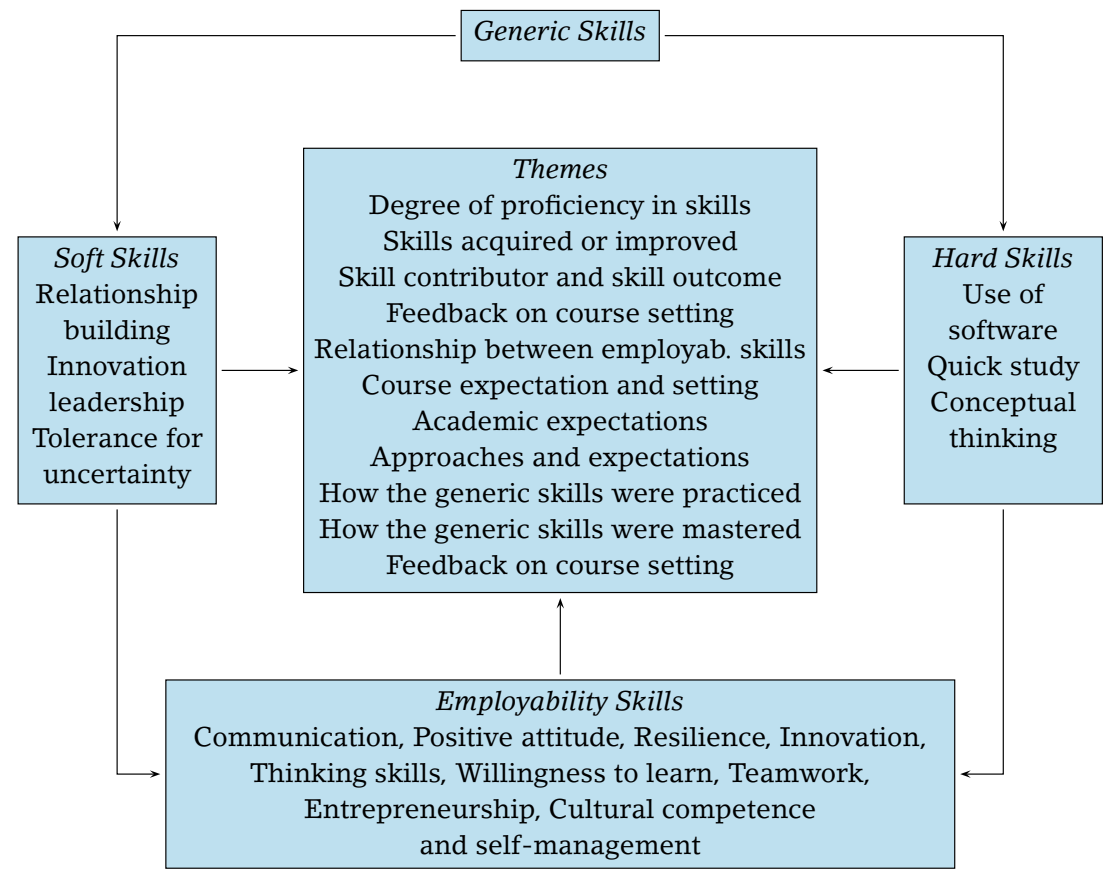

FIGURE 1 The Relationship between Generic Skills and Employability Skills to Themes Extracted during the Thematic Analysis

conceptual thinking) were identified for this investigation. Additionally, 10 core employability skills essential for obtaining and retaining a job in New Zealand were identified for the project. These employability skills were; communication, positive attitude, resilience, innovation, thinking skills, willingness to learn, teamwork, entrepreneurship, cultural competence and self-management. The coding process and thematic analysis technique was utilised to analyse data, and 11 important themes emerged during this process. These themes were; degree of proficiency in skills, skills acquired or improved, skill contributor and skill outcome, feedback on course setting, relationship between employability skills, course expectation and setting, academic expectations, approaches and expectations, how the generic skills were practiced, how generic skills were mastered, and feedback on course setting. Some themes emerged with sub-themes. There were approaches and expectations (with subtheme essential activities and skills provider), how generic skills were practiced (with sub-themes generic skill practices and direct employability skill training), and how generic skills were mastered 
(with sub-theme negation). The relationship between hard skills, employability skills and themes were identified and illustrated in figure 1.

The analysis of data collected from interviews showed the relationship of generic skills to the employability skills for the graduates from New Zealand iтps. The result disclosed that the entire group of employers (managers) gave priority to graduates' employability skills. Based on their employees' (graduates) performances, employers justified each employability skill with sufficient explanations. After comparing the responses received from all three groups of participants (graduates, lecturers and employees), almost all the employability skills of graduates were recognised in the present New Zealand job market. When it comes to graduates' feedbacks, they also indicated that the study experience in ITPs indeed contributed to an increase in their generic skills. The graduates explained how they gained and improved their skills during their study period in the ITP through lectures, assignments, teamwork, class activities, various other study events organised by the institution and other offcampus activities. Most graduates stated that before their studies in ITPS, they were already equipped with some generic skills. However, all of them agreed that the study at Iтр enhanced these skills. Additionally, they indeed learned some totally new skills by studying a specific course or participating in a specific activity. The group consisting of the lecturers in ITPS presented a much more objective and comprehensive understanding as to why and how the current courses and activities were designed. Many skills had been integrated to prepare the present ITP students for the way they had to meet the managers' expectations in the present New Zealand job market.

\section{References}

Ademiluyi, L. F. 2019. 'Employability Skills Needed by Business Education Graduates as Perceived by Business Teachers and Employers of Labour in Two Southwestern Nigerian States.' Business Education Innovation Journal 11 (1): 57-65.

Azim, S., A. Gale, T. Lawlor-Wright, R. Kirkham, A. Khan, and M. Alam. 2010. 'The Importance of Soft Skills in Complex Projects.' International Journal of Managing Projects in Business 3 (3): 387-401.

Bedwell, W. L., S. S. Fiore, and E. Salas. 2014. 'Developing the Future Workforce: An Approach for Integrating Interpersonal Skills into the мвA Classroom.' Academy of Management Learning \& Education 13 (2): 171-86.

Bolisani, E., and A. Oltramari. 2012. 'Knowledge as a Measurable Ob- 
ject in Business Contexts: A Stock-and-Flow Approach.' Knowledge Management Research \& Practice 10 (3): 235-86.

Bratianu, C., 2015. Organizational Knowledge Dynamics: Managing Knowledge Creation, Acquisition, Sharing, and Transformation. Hershey, PA: IGI Global.

Bratianu, C., and E. Vatamanescu. 2017. 'Students' Perception on Developing Conceptual Generic Skills for Business: A Knowledge-Based Approach.' vine Journal of Information and Knowledge Management Systems 47 (4): 490-505.

Braun, V., and V. Clarke. 2006. 'Using Thematic Analysis in Psychology.' Qualitative Research in Psychology 3 (2): 77-101.

Bridgstock, R. 2001. 'The Graduate Attributes We've Overlooked: Enhancing Graduate Employability through Career Management Skills.' Higher Education Research \& Development 28 (1): 31-44.

Cabellero, C. L., and A. Walker. (2010. 'Work Readiness in Graduate Recruitment and Selection: A Review of Current Assessment Methods.' Journal of Teaching and Learning for Graduate Employability 1 (1): 13-25.

Carmeli, A., R. Gelbard, and D. Gefen. 2010. 'The Importance of Innovation Leadership in Cultivating Strategic Fit and Enhancing Firm Performance.' The Leadership Quarterly 21 (3): 339-49.

Cassidy, S. 2006. 'Developing Employability Skills: Peer Assessment in Higher Education.' Education + Training 48 (7): 508-17.

Chan, C. K. Y., and E. T. Y. Fong. 2018. 'Disciplinary Differences and Implications for the Development of Generic Skills: A Study of Engineering and Business Students' Perceptions of Generic Skills.' European Journal of Engineering Education 43 (6): 927-49.

Connor, H., and S. Shaw. 2008. 'Editorial: Graduate Training and Development: Current Trends and Issues.' Education + Training 50 (5): 357-65.

Curtis, D. D. 2004. 'The Assessment of Generic Skills.' In Generic Skills in Vocational Education and Training, edited by J. Gibb: 136-56. Adelaide: National Centre for Vocational Education Research.

Dearing, R. 1997. 'Higher Education in the Learning Society.' Report of the National Committee of Inquiry into Higher Education, Her Majesty's Stationary Office, Norwich.

Duignan, G., S. Casley, C. Fraser, C. Haggerty, S. Hannam, J. Hitchcock, A. Rodrigues, K. Ross, L. Seno, D. Stewart, B. Taylor, and A. Webster 2018. 'Teaching Strategies that Build Employability Skills of Vocational Education Graduates.' Project report of Central Regional Hub-Funded Project, Ako Aotearoa National Centre for Tertiary Teaching Excellence, Wellington.

Ferguson, J. 2010. 'An Overview and Discussion of Research Supporting the Concept of a Generic "Soft" Skills Framework in Tertiary 